\title{
Optimising the Improvement of a Global Industrial Performance Based on AHP and Sugeno Integral Aggregation: Case Study in Moroccan Automotive Suppliers
}

\author{
Mohamed Tarek CHAHID ${ }^{1,4}$, Jamila EL ALAMI ${ }^{2}$, Aziz SOULHI ${ }^{3}$ \& Nourdine EL ALAMI ${ }^{1}$ \\ ${ }^{1}$ University Mohammed V-Agdal, Mohammadia School of Engineers, Rabat, Morocco \\ ${ }^{2}$ University Mohammed V-Agdal, Superior School of Technology Sale, Sale, Morocco \\ ${ }^{3}$ National Superior School of Mines of Rabat, Rabat, Morocco \\ ${ }^{4}$ Moroccan Institute for Training in Automotive Industry (IFMIAC), Casablanca, Morocco \\ Correspondence: Mohamed Tarek CHAHID, Institut de Formation aux Métiers de l'Industrie Automobile de \\ Casablanca, Voie EC 03, Nouvelle Zone Industrielle, Ahl Loughlam, Sidi Bernoussi, BP 1152, Casablanca, \\ Morocco. Tel: 212-529-028-865. E-mail: t.chahid@giac1.org
}

Received: September 22, $2014 \quad$ Accepted: October 14, $2014 \quad$ Online Published: December 10, 2014

doi:10.5539/mas.v9n2p96 URL: http://dx.doi.org/10.5539/mas.v9n2p96

\begin{abstract}
The performance measurement systems (PMS) in the industry are defined in terms of various measures to be combined for global performance. The proposed approach treats with a qualitative approach for multicriteria decision with the improvement strategy of an overall industrial performance. The approach is based on a AHP and Sugeno integral aggregation operator, permits to express the global performance, according to the fuzzy set theory of appropriate Key Performance Indicators (KPI), the nonlinearity of this model, makes data ambiguous in the process of multicriteria decision-making.

Hence, this manuscript is a contribution to the selection of the strategy of the improvement of the overall performance. The approach applies to the Moroccan Automotive Suppliers to evaluate three strategies alternatives by using a fuzzy Sugeno Integral technique to deal with the complex interrelationships aspects between KPI.
\end{abstract}

Keywords: performance measurement systems, sugeno integral aggregation, cost, global performance, Improvement strategy

\section{Introduction}

In the complex real world, fuzzy logic is usually used to treat with the problems of ambiguity, particularly those associated with subjective sensitivity. Conventional analytical approaches are insufficient for dealing with such complex situations, because, the criterions are generally interconnected (Berrah and Clivelle, 2007).

Therefore, this work adopted the fuzzy logic methodology to deal with the imprecision of human perception. The fuzzy integral is more appropriate when the criteria are connected.

Based on the intuition of the managers, the strategies of development in corporations are fundamentally complex analytical processes. Several strategies have to be assessed considering a vast body of data that are often hard to quantify (Berrah et al., 2008).

Hence, this paper implements Sugeno fuzzy integral to estimate every alternative strategy in a complex environment with multicriteria dimensions. The fuzzy integral was used to assess the performance of several strategies to reach the highest overall performance. It permits to have a better comprehension of this more complex (i.e. Nonlinear) performance model.

To date, there have been no researches which using $\lambda$-fuzzy measures and Sugeno integrals to select a best improvement strategy in MCDM (Berrah, 2013).

This work is focused on decision-support tools that could help managers to better plan performances improvements. to the company strategy to reach a goal while minimizing costs.

This work is related to the concept of efficient improvement; the contribution of criterion "Price availability" to the overall performance improvement has been added to KPI already identified in the Moroccan automotive sector. 
More precisely, we focused on the performance aggregation problem. Also, we give a review of the fuzzy MCDM, with the nonadditive fuzzy integral. Then, a case study is illustrated to show the effectiveness of the proposed model in the context of the Moroccan automotive suppliers. And last, we present a discussion of the results and their implication. Finally, the concluding observations are illustrated.

\subsection{Aggregation of Performance Measurement Expressions}

The performance of the manufacturing system is determined by the configuration of equipments, manpower, data flows, process and technology, this configuration give manufacturers competitive advantage (Bititci et al., 2001). So the company's performance is determined by its ability to achieve the objectives set by the business strategy (Michalska, 2005).

The main goal of PMS is to transform the data measurement into information to assess the effectiveness and efficiency of action. It is in fact the establishment of objectives, collect, analysis and interpretation of performance measures. On the other hand, The system should function as a thermostat, in a way that the process aim to evaluate the inequality between the actual result and the target, to identify those critical inequalities, to appreciate the roots of dysfunctions in order to introduce corrective and preventive actions (Melnyk et al., 2014).

In this sense, so-called performance measurement systems (PMS's) are the instruments to support decision-making (Kueng and Krahn, 1999). In other word, a PMS can be seen as a multicriteria tool, based on performance expressions (Suwingjo et al., 2000).

The main difficulty in the design of a performance measurement system concerns the determination of expressions of performance that are useful for decision-making. In fact, the distinction should be made between the global objectives of the business; which are broken down along organizational levels (Ducq et al., 2001).

To make a decision, all expressions of performance must be treated to compare different situations that occur in the industrial context. Therefore, two types of performance expressions are involved in a PMS: elementary expressions that identify degrees reached different objectives, and the aggregate expressions that are the synthesis of elementary performance expressions in the overall objectives. Also, aggregation expressions define the priorities in the strategy and give the choice of the scenarios based on their expressions of basic performance (Clivelle et al., 2006).

The performance aggregation is usually defined as the result step of the objective break-down. The aggregation treats with the arrangement of all the performance expressions concerned.

Two kinds of approach are known, the monocriterion PMS and the multi-criteria PMS. In the monocriterion PMS, the clause to the aggregation is that all the performance expressions are formulated in a universal reference, such as delay, cost, quality (Azzone et al., 1991). So, the global performance is the result of the sum of elementary expression (cost, delay...).

This aggregation model based on mono-criterion PMS approach is no more adapted as an instrument of decision making, in the current industrial context. Consequently, it's necessary to express performance in multicriteria form (Neely, 1999). The weighted arithmetic mean (WAM) operator aggregated the involved elementary performances to match the global performance. These weights measure the hierarchical links of the elementary expressions (Ducq et al., 2001).

\subsection{Fuzzy Measurement}

The fuzzy sets basis is the fact that the building blocks of human analysis are not numbers but linguistic markers; in that way, fuzzy logic follows this concept and utilized estimated information to get exact resolutions (Takagi and Sugeno, 1985).

These data are formulated in numerical and/or linguistic values. So, performance formulations are exact or inexact, sure or doubtful (Berrah et al., 2000).

All measurements are related to a vagueness. The ambiguity of the measurement reveals the insufficiency of precise knowledge, and the fuzzy measurements become a synergic method of processing measurements (Reznik and Dabke, 2004).

Fuzzy Multicriteria decision making has been commonly utilized to resolve decision making aspects concerning multicriteria assessment and the choice of options.

The fuzzy concepts have the following features: 1) their structures capture the dependency between inputs and outputs of a system; 2) the fuzzy linguistic sets give ambiguities; 3) they model nonlinear system; 4) the singular and linguistic outputs are created; 5) they are insensible to random noise (Wang, and Chen, 2014). 
The AHP is the main utilized tool by researchers and managers in multi criteria decision making. The fields of AHP's use are planning, choosing best scenarios, resource management (Vaidya and Kumar, 2006). AHP can mix different kinds of data in multilevel decision configuration to get a full visualization of the manufacturing organization (Hernandez-Matias et al., 2008).

In scholarly literature, over 2000 AHPs applications were counted; they are used when resolutions need quantitative and qualitative aspects (Subramanian \& Ramanathan, 2012).

\subsection{Fuzzy Integral}

The relationship between criteria affect positively or negatively assessments of the decision to accept or reject a project. This reality cannot be modeled with a traditional best compromise strategy. Aggregation based on fuzzy integrals articulate a multiplicity of decision maker behaviors (Buyukozkan \& Ruan, 2010).

In classic multiple criteria assessment methods, each criterion must not be dependent of the others. So, the relations and mutual effects in an industrial environment cannot be treated with the classic additive measures (Berrah et al., 2004).

The application of fuzzy integral as an aggregation operator in Multi-Criteria Decision Making was offered by Grabisch (Grabisch, 1995). The notion of the fuzzy integral, introduced by Sugeno (Sugeno \& Takahiro, 1993), can be used to multi-criteria evaluation.

The distinctive quality of a fuzzy integral is the ability to represent interactions between criterion, ranging negative interaction to positive interaction, which surmounts the inadequacy of modeling reliant factors as self-regulating sets (Grabisch, 1995).

In addition, in this context, the fuzzy integral family generalizes the WAM (Weighted Arithmetic Mean) operator by quantifying interactions between factors (Grabisch, 1995).

In traditional integrals, we have signed the measure, but in fuzzy integrals we have fuzzy measure, the divergence between them is non-additively, in fuzzy integrals we have additive and non additive but in classic integral we have additive only. Thus, the structured configuration assessment of human subjective DM fuzzy integrals (Jeng, 2011). It can be said that the Choquet integral is suitable for cardinal aggregation, where the number has real meaning, while the Sugeno integral is more appropriated for ordinal aggregation, where only rank make sense (Sugeno and Takahiro, 1993).

\subsection{The Sugeno Integral}

The main reason for the choice of $\lambda$-fuzzy measure ( $(\lambda$ is also called the degree of interaction) is that fuzzy measures for subsets of information sources is easy to calculate and the number of fuzzy measures to be known is reduced from $2^{n}-2$ into $\mathrm{n}$ due to the $\lambda$-rule (Sugeno and Takahiro, 1993).

Let a finite set $X=\left\{x_{1}, x_{2}, \ldots, x_{n}\right\}$ be a set of information sources and a fuzzy density $g^{i}=g\left(\left\{x_{1}\right\}\right)$ describe the degree of importance of each source $x i$. Let the set of $X$ to be $2 X$.

Then a $\lambda$-fuzzy measure is a real-valued nonadditive set function $\mathrm{g}: 2^{X} \rightarrow(0,1)$.

Satisfying the following properties:

$$
\begin{gathered}
g(\varnothing)=0 ; g(X)=1 \\
g(A) \leq g(B) i f A \subset B \subset X \\
\forall A, B \subseteq X a n d A \cap B=\varnothing \\
g(A \cup B)=g(A)+g(B)+\lambda g(A) g(B)
\end{gathered}
$$

The parameter $\lambda$ in Equation (3) can be determined by solving a polynomial equation (4). The equation is derived by using the second boundedness property in equation (1) and the rule $\lambda$-rule in equation (3).

$$
\lambda+1=\prod_{i=1}^{n}\left(1+\lambda g^{i}\right)
$$

Let an evaluation function $f: X \rightarrow[0,1]$ be sorted in ascending order such that $f\left(x_{(1)}\right) \leq f\left(x_{(2)}\right) \leq \ldots \leq f\left(x_{(n)}\right)$.

For partial information source $x_{i}$, sugeno fuzzy measure for a subset, can be recursively characterized by the equation (5). Here, $f\left(x_{(i)}\right)$ denotes the $i$-th smallest function:

$$
g\left(A_{(i)}\right)=g^{(i)}+g\left(A_{(i+1)}\right)+\lambda g^{(i)}+g\left(A_{(i+1)}\right) \text { with } g\left(A_{(i+1)}\right)=0
$$


Sugeno integral can be viewed as an aggregation operation process between evaluation functions and fuzzy measures representing the importance degrees of partial information. Discrete Sugeno integral (SI) with respect to Sugeno fuzzy measure $\mathrm{g}\left(\mathrm{A}_{(\mathrm{I})}\right)$ over $\mathrm{X}$ is formulated by:

$$
\begin{aligned}
& \int f(x) d g_{\lambda}=\operatorname{Max}_{i=1}^{n}\left\{\operatorname{Min}\left[f\left(x_{(i)}, g\left(A_{(i)}\right)\right]\right\}\right. \\
& \text { Where } f\left(x_{(1)}\right) \leq f\left(x_{(2)}\right) \leq \ldots \leq f\left(x_{(n)}\right) .
\end{aligned}
$$

As a WAM approach uses additive probability measures as weighting factors, the WAM approach does not deal with the interaction among the criteria. On the contrary, the SI approach based on $\lambda$-fuzzy measures handles various grades of interaction among the criteria (Sugeno and Takahiro, 1993).

It is found that the aggregation method selected in a modeling stage had an effect on both of ranking and overall score. Furthermore, this Sugeno integral approach can provide more easily interpretable information than the classical WAM does. Thus, it suggests that the proposed approach is one of beneficial tools to aggregate two types of evidence. Also, a faster processing is realized by the Sugeno Integral (Wang, and Chen, 2014).

\section{Method}

\subsection{Context of the Application}

Manufacturing performance measurement in the automotive industry is important in emerging countries, especially in Morocco, which is considered as the best delivery platform for the European market with over 120 equipment manufacturers, producing near the amount of $€ 2500$ million, and employing 60000 employees resulting in the part of exported production value at over $90 \%$ (AMICA, 2012).

To date, there are no a performance measurement study or model developed in morocco (AMICA, 2012), so we propose a systematic scoring method for all Key Performance Indicators (KPI) in order to establish a performance measurement model that reflects the main characteristics of the Moroccan automotive suppliers. The difficulty to be solved is to identify the smallest costly strategy of the elementary performances to achieve an expected overall performance.

The propositions of this manuscript initiated from the manufacturers' demand for an assistance to better understand the factors of success of Moroccan automotive suppliers and to monitor strategic action plans.

\subsection{Research Design}

To reflect the multidimensional aspect of performance, the use of questionnaire was utilized to identify improvement areas. The questionnaire was administrated during 2012 to 28 Moroccan automotive suppliers from different nationalities (USA, Japan, Germany, Spain, France...) that are employing 25.000 employees.

A total of 24 responses was received 17 of which were usable, yielding the response rate of $61 \%$. The non response bias is a result of the confidentiality of these KPIs.

The proposed method consists of the AHP and Sugeno integral. The evaluation procedure of the strategy improvement project. The first step is to identify the multiple criteria that are considered in the decision-making process for the DMs to make an objective decision. The survey was used to define the KPI affection the global performance for the Moroccan Automotive suppiers, then, we integrate the "Price Availability" criterion in the global performance formula to take account to cost constraint.

The weights can be estimated by the AHP. Finally, we conducted two algorithms in order to compare the efficiency of each one.

The first one was the linear model that quantifies the overall performance by calculating a weighted mean of all performance expressions coupled with the different diverse criteria that are translated into a common reference. Consequently, the three strategies of improvement (Quality security, Human resources, Machine Management) were ranked. The application of the second algorithm (the Sugeno integral) was performed to aggregate the elementary performance expression, to achieve the ranking of those strategies.

The Sugeno integral was performed in three steps: the construction of Objectives, $\lambda$-fuzzy measure calculation and the results of Sugeno integral. 


\subsection{Linear Model of the Moroccan Automotive Suppliers}

\subsubsection{Quantification of Elementary Performance Expression}

We have identified 6 KPI: Customer Complaint (Cc), Scrap Rate (Qs), Machine Availability (Ma), Absenteeism (Ab), Number of Occupational Injuries (Oi) and Training Days per Person (Tdb) as Key Performance Factors of Moroccan automotive sector (Chahid et al., 2014). Then, we add Price Availability (Pa) as cost parameter in the process of decision making.

Hence, they are used in the calculation of the overall performance. In fact, each KPI are coupled with the appropriate weight $\left(r_{1}, r_{2}, r_{3}, r_{4}, r_{5}, r_{6}, r_{7}\right.$ respectively). This association leads us to adopt the AHP method that allows KPIs to be compared in pairs to define their relative importance through expert judgment. Then each KPI is assigned an absolute importance (weight) based on previous respective importance on a scale ratio, with the constraint that these weights sum up to 1 .

The AHP method is currently the most common method used in the industrial application to aggregate performance expressions. The outranking method compares the different criteria in five levels of importance to global satisfaction: "equal", "low", "critical", "proven" and "absolute" respectively quantified at 1, 3, 5, 7 and 9. Intermediate values between two levels are accepted (Clivelle, 2004). The experts assign an intensity number that represents the true preference of each reason with respect to other reasons. The intensity of factor $i$ over factor $j$ is equal to $\mathrm{a}_{i j}$, and the intensity importance of factor $j$ over $i$ is equal to $1 / \mathrm{a}_{i j}$. If we have $n$ factors to compare, we develop a $n * n$ matrix A to represent the importance of these factors:

$$
\left(\begin{array}{ccc}
a_{1 n} & \ldots & a_{1 n} \\
\vdots & \ddots & \vdots \\
a_{n 1} & \cdots & a_{n n}
\end{array}\right)=\mathrm{A}
$$

Where $n$ is the order of the matrix

To determine the weight for each KPI, interviews of experts (General Managers, Leaders of the Moroccan Association of Automotive industry) in the Moroccan automotive industry were performed using pairwise comparisons that were given 15 pairwise comparisons as shown in table 1.

Table 1. Pairwise comparison matrix

\begin{tabular}{lccccccc}
\hline & $\mathrm{Cc}$ & $\mathrm{Qs}$ & $\mathrm{Ma}$ & $\mathrm{Ab}$ & $\mathrm{Oi}$ & $\mathrm{Tdb}$ & $\mathrm{Pa}$ \\
\hline $\mathrm{Cc}$ & 1 & $1 / 4$ & $1 / 7$ & 5 & 6 & $1 / 5$ & $1 / 5$ \\
$\mathrm{Qs}$ & 4 & 1 & $1 / 4$ & 6 & 7 & $1 / 2$ & $1 / 4$ \\
$\mathrm{Ma}$ & 7 & 4 & 1 & 8 & 9 & 3 & 2 \\
$\mathrm{Ab}$ & $1 / 5$ & $1 / 6$ & $1 / 8$ & 1 & 5 & $1 / 7$ & $1 / 6$ \\
$\mathrm{Oi}$ & $1 / 6$ & $1 / 7$ & $1 / 9$ & $1 / 5$ & 1 & $1 / 8$ & $1 / 7$ \\
$\mathrm{Tdb}$ & 5 & 2 & $1 / 3$ & 7 & 8 & 1 & 3 \\
$\mathrm{~Pa}$ & 5 & 4 & $1 / 2$ & 6 & 7 & $1 / 3$ & 1 \\
SUM & 22,37 & 11,56 & 2,46 & 33,20 & 43,00 & 5,30 & 6,76 \\
\hline
\end{tabular}

Table 2 represents the matrix $\mathrm{A} 1$ as the normalized comparison matrix that is calculated as shown below:

$$
\left(\begin{array}{ccc}
a_{1 n}^{\prime} & \ldots & a_{1 n}^{\prime} \\
\vdots & \ddots & \vdots \\
a_{n 1}^{\prime} & \cdots & a_{n n}^{\prime}
\end{array}\right)=\mathrm{A}_{1} \text { and } a^{\prime}=\frac{a_{i j}}{\sum_{i, j=1}^{n} a_{i j}} \text { for } i, j=1,2, \ldots, n,
$$

Table 2. Matrix A1

\begin{tabular}{cccccccc}
\hline $\mathrm{a}^{\prime}{ }_{\mathrm{ij}}$ & \multicolumn{1}{c}{$\mathrm{Cc}^{\prime}$} & \multicolumn{1}{c}{$\mathrm{Qs}^{\prime}$} & $\mathrm{Ma}{ }^{\prime}$ & $\mathrm{Ab}$ & $\mathrm{Oi}$ & \multicolumn{1}{c}{$\mathrm{Tdb}^{\prime}$} & $\mathrm{Pa}$ \\
\hline $\mathrm{Cc}^{\prime}$ & $(1) / 22,37$ & $(1 / 4) / 11,56$ & $(1 / 7) / 2,46$ & $(5) / 33,2$ & $(6) / 43,00$ & $(1 / 5) / 5,30$ & $(1 / 5) / 6,76$ \\
$\mathrm{Qs}^{\prime}$ & $(4) / 22,37$ & $(1) / 11,56$ & $(1 / 4) / 2,46$ & $(6) / 33,2$ & $(7) / 43,00$ & $(1 / 2) / 5,30$ & $(1 / 4) / 6,76$ \\
$\mathrm{Ma}^{\prime}$ & $(7) / 22,37$ & $(4) / 11,56$ & $(1) / 2,46$ & $(8) / 33,2$ & $(9) / 43,00$ & $(3) / 5,30$ & $(2) / 6,76$ \\
$\mathrm{Ab}$ & $(1 / 5) / 22,37$ & $(1 / 6) / 11,56$ & $(1 / 8) / 2,46$ & $(1) / 33,2$ & $(5) / 43,00$ & $(1 / 7) / 5,30$ & $(1 / 6) / 6,76$ \\
$\mathrm{Oi}^{\prime}$ & $(1 / 6) / 22,37$ & $(1 / 7) / 11,56$ & $(1 / 9) / 2,46$ & $(1 / 5) / 33,2$ & $(1) / 43,00$ & $(1 / 8) / 5,30$ & $(1 / 7) / 6,76$ \\
$\mathrm{Tdb}$ & $(5) / 22,37$ & $(2) / 11,56$ & $(1 / 3) / 2,46$ & $(7) / 33,2$ & $(8 / 43,00)$ & $(1) / 5,30$ & $(3) / 6,76$ \\
\hline
\end{tabular}




\begin{tabular}{cccccccc}
\hline $\mathrm{a}^{\prime}{ }_{\mathrm{ij}}$ & $\mathrm{Cc}^{\prime}$ & $\mathrm{Qs}^{\prime}$ & $\mathrm{Ma}^{\prime}$ & $\mathrm{Ab}$ & $\mathrm{Oi}^{\prime}$ & $\mathrm{Tdb}^{\prime}$ & $\mathrm{Pa}$ \\
\hline $\mathrm{Pa}$ & $(5) / 22,37$ & $(4) / 11,56$ & $(1 / 2) / 2,46$ & $(6) / 33,2$ & $(7) / 43,00$ & $(1 / 3) / 5,30$ & $(1) / 6,76$ \\
\hline
\end{tabular}

The table 3 calculates the eigenvalue and the eigenvector

$$
\left(\begin{array}{l}
w_{1} \\
w_{2} \\
\vdots \\
w_{n}
\end{array}\right)=w \quad \text { and } \omega \mathrm{t}=\frac{\sum_{i, j=1}^{n} a_{i j}^{\prime}}{n} \text { for } i, j=1,2, \ldots, n,
$$

The respective weight of each KPI $\left(\mathrm{r}_{1}, \mathrm{r}_{2}, \mathrm{r}_{3}, \mathrm{r}_{4}, \mathrm{r}_{5}, \mathrm{r}_{6}\right)$ is given in table 3 .

Table 3. Determination of KPIs' weight

\begin{tabular}{|c|c|c|c|c|c|c|c|c|}
\hline & & Qs & $\mathrm{Ma}$ & $\mathrm{Ab}$ & Oi & $\mathrm{Tdb}$ & $\mathrm{Pa}$ & Weight \\
\hline $\mathrm{Cc}$ & 0,04 & 0,02 & 0,06 & 0,15 & 0,14 & 0,04 & 0,03 & 0,07 \\
\hline Qs & 0,18 & 0,09 & 0,10 & 0,18 & 0,16 & 0,09 & 0,04 & 0,12 \\
\hline Ma & 0,31 & 0,35 & 0,41 & 0,24 & 0,21 & 0,57 & 0,30 & 0,34 \\
\hline $\mathrm{Ab}$ & 0,01 & 0,01 & 0,05 & 0,03 & 0,12 & 0,03 & 0,02 & 0,04 \\
\hline Oi & 0,01 & 0,01 & 0,05 & 0,01 & 0,02 & 0,02 & 0,02 & 0,02 \\
\hline $\mathrm{Tdb}$ & 0,22 & 0,17 & 0,14 & 0,21 & 0,19 & 0,19 & 0,44 & 0,22 \\
\hline $\mathrm{Pa}$ & 0,22 & 0,35 & 0,20 & 0,18 & 0,16 & 0,06 & 0,15 & 0,19 \\
\hline
\end{tabular}

The paradigm of the Moroccan automotive industry is the improvement of materials and the availability of manpower; also, the "Cost" dimension and the safety at work and the internal climate are integrated in the overall performance of these manufactories.

Traditionally, most plant managers focused on the triangle of (Cost, Quality and Delay). Subsequently, our model shows that there are other Key Factor of Success (Training, internal climate and Safety) which should be integrated in their strategic, tactical and operational management.

\subsubsection{Choice of Strategies based on the Linear Model of the Moroccan Automotive Suppliers}

The global performance (GP) is expressed, based on the WAM as the aggregation operator, in the formula below (Chen, 2008):

$$
G P=100 *\left(\mathrm{P}_{A K P I} * \sum_{i=1}^{7} r_{i}\right)
$$

Therefore, the formula for overall performance of Moroccan automotive suppliers is calculated as follows:

$$
G P=100 *\left(0,07 \mathrm{P}_{C c}+0,12 \mathrm{P}_{Q s}+0,34 \mathrm{P}_{M a}+0,04 \mathrm{P}_{A b}+0,02 \mathrm{P}_{O i}+0,22 \mathrm{P}_{T d b} 0,19 \mathrm{P}_{P a}\right)
$$

Relevant performance indicators and their relationships to strategic and operational goals need to be determined and analyzed. (Popova and Sharpanskykh, 2010)

The alternative improvement strategies adopted in this research are summarized following the KSF (Key Success Factors) of Moroccan Automotive suppliers: $\left(\mathrm{S}^{\mathrm{QS}}\right)$ Quality and security, $\left(\mathrm{S}^{\mathrm{HR}}\right)$ Human Resources \& climate social, $\left(\mathrm{S}^{\mathrm{MM}}\right)$ Maintenance Management.

By applying the WAM operator, an overall performance of strategies, can be expressed as shown in Table 4 . The decision-maker can now rank the strategies $\mathrm{S}^{\mathrm{QS}} \mathrm{S}^{\mathrm{HR}} \mathrm{S}^{\mathrm{MM}}$. The conclusion is to retain the best strategy with regards to the overall performance: 
Table 4. Overall performance of strategies

\begin{tabular}{lllllllll}
\hline & $\mathrm{P}_{\mathrm{Cc}}$ & $\mathrm{P}_{\mathrm{QS}}$ & $\mathrm{P}_{\mathrm{Ma}}$ & $\mathrm{P}_{\mathrm{Ab}}$ & $\mathrm{P}_{\mathrm{Oi}}$ & $\mathrm{P}_{\mathrm{Tdb}}$ & $\mathrm{P}_{\mathrm{Pa}}$ & $\mathbf{G P}$ \\
\hline $\mathrm{S}^{\mathrm{QS}}$ & 1 & 0.9 & 0.5 & 0,2 & 0,8 & 0,7 & 0.5 & $\mathbf{0 , 6 2}$ \\
$\mathrm{S}^{\mathrm{HR}}$ & 0,8 & 0,8 & 0,7 & 0,8 & 0.5 & 1 & 0.7 & $\mathbf{0 , 7 8}$ \\
$\mathrm{S}^{\mathrm{MM}}$ & 0,8 & 0,9 & 1 & 0,1 & 0.5 & 0,7 & 0,9 & $\mathbf{0 , 8 4}$ \\
\hline
\end{tabular}

The decision-maker can rank the best strategy $\left(\mathrm{S}^{\mathrm{QS}}, \mathrm{S}^{\mathrm{HR}}, \mathrm{S}^{\mathrm{MM}}\right)$ by retaining the best strategy with regards to the overall performance, in this case, the choice of "Machine Management" is chosen in the first rank, then the "Human resource" strategy occupies the second place followed by the "Quality security" strategy.

However, the choice of any strategy does not provide indications about reducing the investment because the business policy is too generous regarding a key factor or simply maintain investment because a satisfactory level has been reached.

Furthermore, the decision maker cannot combine performance parameters linearly in a manner to assist management in formulating the most suitable decision. So, the aim of this research is to treat with the complex and dynamic interrelationships aspects of KPIs.

\subsection{The Aggregated Performance Expression by Sugeno Integral}

\subsubsection{Construction of Objectives}

We introduce the notions of a space of states $X=\left\{x_{1}, x_{2}, \ldots, x_{n}\right\}$ and a decision space (a space of alternatives). $S=\left\{s_{1}, s_{2}, \ldots, s_{n}\right\}$

We consider a decision model in which $n$ alternatives $s_{1}, s_{2}, \ldots, s_{n} \in S$ act as strategies used to improve the overall performance. The strategies should influence $m$ states $s_{1}, s_{2}, \ldots, s_{n} \in S$, which are identified with $m$ KPI corresponding to KSF.

Table 5. The efficiency of the elementary performance

\begin{tabular}{ll}
\hline Effectiveness & $U_{(g)}$ \\
\hline None & 0 \\
Almost none & 0.1 \\
Very little & 0.2 \\
Little & 0.3 \\
Rather little & 0.4 \\
Medium & 0.5 \\
Rather large & 0.6 \\
Large & 0.7 \\
Very large & 0.8 \\
Almost complete & 0.9 \\
Complete & 1 \\
\hline
\end{tabular}

The expert's opinion has judged the relationship between the efficiency of the elementary performance and strategies following the table 5 . We express the connection in the table 6.

Table 6. Relationship among Efficiency of the Elementary Performance and Stategies

\begin{tabular}{|c|c|c|c|c|c|c|c|}
\hline & $\mathrm{P}_{\mathrm{Cc}}$ & $\mathrm{P}_{\mathrm{Qs}}$ & $\mathrm{P}_{\mathrm{Ma}}$ & $\mathrm{P}_{\mathrm{Ab}}$ & $\mathrm{P}_{\mathrm{Oi}}$ & $\mathbf{P}_{\mathrm{Tdb}}$ & $\mathrm{P}_{\mathrm{Pa}}$ \\
\hline $\mathrm{S}^{\mathrm{QS}}$ & $\begin{array}{l}\text { complete } \\
f\left(x_{1}\right)=g_{11}=1\end{array}$ & $\begin{array}{l}\text { Almost } \\
\text { complete } \\
f\left(x_{2}\right)=g_{12}=0.9\end{array}$ & $\begin{array}{l}\text { Medium } \\
f\left(x_{3}\right)=g_{13}=0.5\end{array}$ & $\begin{array}{l}\text { Very } \quad \text { little } \\
f\left(x_{4}\right)=g_{14}=0.2\end{array}$ & $\begin{array}{l}\text { Very } \quad \text { large } \\
f\left(x_{5}\right)=g_{15}=0.8\end{array}$ & $\begin{array}{l}\text { large } \\
f\left(x_{6}\right)=g_{16}=0.7\end{array}$ & $\begin{array}{l}\text { Medium } \\
f\left(x_{7}\right)=g_{17}=0.5\end{array}$ \\
\hline $\mathrm{S}^{\mathrm{HR}}$ & $\begin{array}{l}\text { Very } \quad \text { large } \\
f\left(x_{1}\right)=g_{21}=0.8\end{array}$ & $\begin{array}{l}\text { Very } \quad \text { large } \\
f\left(x_{2}\right)=g_{22}=0.8\end{array}$ & $\begin{array}{l}\text { large } \\
f\left(x_{3}\right)=g_{23}=0.7\end{array}$ & $\begin{array}{l}\text { Very } \quad \text { large } \\
f\left(x_{4}\right)=g_{24}=0.8\end{array}$ & $\begin{array}{l}\text { Medium } \\
f\left(x_{5}\right)=g_{25}=0.5\end{array}$ & $\begin{array}{l}\text { complete } \\
f\left(x_{6}\right)=g_{26}=1\end{array}$ & $\begin{array}{l}\text { large } \\
f\left(x_{7}\right)=g_{27}=0.7\end{array}$ \\
\hline $\mathrm{S}^{\mathrm{MM}}$ & $\begin{array}{l}\text { Very } \quad \text { large } \\
f\left(x_{1}\right)=g_{21}=0.8\end{array}$ & $\begin{array}{l}\text { Almost } \\
\text { complete } \\
f\left(x_{2}\right)=g_{32}=0.9\end{array}$ & $\begin{array}{l}\text { complete } \\
f\left(x_{3}\right)=g_{33}=1\end{array}$ & $\begin{array}{l}\text { Almost } \quad \text { none } \\
f\left(x_{4}\right)=g_{34}=0.1\end{array}$ & $\begin{array}{l}\text { Medium } \\
f\left(x_{5}\right)=g_{35}=0.5\end{array}$ & $\begin{array}{l}\text { large } \\
f\left(x_{6}\right)=g_{36}=0.7\end{array}$ & $\begin{array}{l}\text { Almost } \\
\text { complete } \\
f\left(x_{7}\right)=g_{37}=0,9\end{array}$ \\
\hline
\end{tabular}




\subsubsection{Construction of Sugeno Integral}

The weights $w_{1}, w_{2}, w_{3}, \ldots, w_{n}, W$ act as the ranges of the function $\mathrm{g}_{\lambda}: X \rightarrow W=[0,1]$

$$
w_{1=} g_{\lambda}\left(x_{1}\right), w_{2}=g_{\lambda}\left(x_{2}\right), w_{3}=g_{\lambda}\left(x_{3}\right), \ldots, w_{n}=g_{\lambda}\left(x_{n}\right) .
$$

So, $w_{1}=w_{C c}=g_{\lambda}\left(x_{1}\right)=0,07 ; w_{2}=w_{Q s}=g_{\lambda}\left(x_{2}\right)=0,12 ; w_{3}=w_{M a}=g_{\lambda}\left(x_{3}\right)=0,34 ; w_{4}=w_{A b}=g_{\lambda}\left(x_{4}\right)=0,04$;

$$
w_{5}=w_{O i}=g_{\lambda}\left(x_{5}\right)=0,02 ; w_{6}=w_{T d b}=g_{\lambda}\left(x_{6}\right)=0,22 ; w_{7}=w_{P a}=g_{\lambda}\left(x_{7}\right)=0,19
$$

According to (4)

$$
\lambda+1=\prod_{i=1}^{n}\left(1+\lambda g^{i}\right)
$$

We had the polynomial equation below:

$$
0=0.39 \lambda^{2}+0.75 \lambda^{3}+0.008 \lambda^{4}+0.00041 \lambda^{5}+0.0000105 \lambda^{6}+9.550 .10^{-08} \lambda^{7}
$$

And the roots of the above equation will be

$$
\lambda=\{0 ; 0 ;(-0.523) ;(-64.689343+34.289641) ;(-64.689343-34.289641 \mathrm{i}) ;(9.9769409+36.84507 \mathrm{i}) ;
$$

$(9.9769409-36.84507 i)\}$

But $\lambda \in(-1, \infty)$

We will take $\lambda=-0.523$ only, because $\lambda=0$ is additively.

If $\lambda=-0.523$ then:

\begin{tabular}{|l|l|}
\hline$g(x 1, x 2)$ & 0,1856068 \\
\hline$g(x 1, x 3)$ & 0,3975526 \\
\hline$g(x 1, x 4)$ & 0,1085356 \\
\hline$g(x 1, x 5)$ & 0,0892678 \\
\hline$g(x 1, x 6)$ & 0,2819458 \\
\hline$g(x 1, x 7)$ & 0,2530441 \\
\hline$g(x 2, x 3)$ & 0,4386616 \\
\hline$g(x 2, x 4)$ & 0,1574896 \\
\hline$g(x 2, x 5)$ & 0,1387448 \\
\hline$g(x 2, x 6)$ & 0,3261928 \\
\hline$g(x 2, x 7)$ & 0,2980756 \\
\hline$g(x 3, x 4)$ & 0,3728872 \\
\hline$g(x 3, x 5)$ & 0,3564436 \\
\hline$g(x 3, x 6)$ & 0,5208796 \\
\hline$g(x 3, x 7)$ & 0,4962142 \\
\hline$g(x 4, x 5)$ & 0,0595816 \\
\hline$g(x 4, x 6)$ & 0,2553976 \\
\hline$g(x 4, x 7)$ & 0,2260252 \\
\hline$g(x 5, x 6)$ & 0,2376988 \\
\hline$g(x 5, x 7)$ & 0,2080126 \\
\hline$g(x 6, x 7)$ & 0,3881386 \\
\hline & \\
\hline
\end{tabular}

\begin{tabular}{|l|r|}
\hline $\mathrm{g}(\mathrm{x} 1, \mathrm{x} 2, \mathrm{x} 3)$ & 0,492602199 \\
\hline $\mathrm{g}(\mathrm{x} 1, \mathrm{x} 2, \mathrm{x} 4)$ & 0,221723906 \\
\hline $\mathrm{g}(\mathrm{x} 1, \mathrm{x} 2, \mathrm{x} 5)$ & 0,203665353 \\
\hline $\mathrm{g}(\mathrm{x} 1, \mathrm{x} 2, \mathrm{x} 6)$ & 0,384250882 \\
\hline $\mathrm{g}(\mathrm{x} 1, \mathrm{x} 2, \mathrm{x} 7)$ & 0,357163052 \\
\hline $\mathrm{g}(\mathrm{x} 1, \mathrm{x} 3, \mathrm{x} 4)$ & 0,4292358 \\
\hline $\mathrm{g}(\mathrm{x} 1, \mathrm{x} 3, \mathrm{x} 5)$ & 0,4133942 \\
\hline $\mathrm{g}(\mathrm{x} 1, \mathrm{x} 3, \mathrm{x} 6)$ & 0,571810198 \\
\hline $\mathrm{g}(\mathrm{x} 1, \mathrm{x} 3, \mathrm{x} 7)$ & 0,548047798 \\
\hline $\mathrm{g}(\mathrm{x} 1, \mathrm{x} 4, \mathrm{x} 5)$ & 0,127400318 \\
\hline $\mathrm{g}(\mathrm{x} 1, \mathrm{x} 4, \mathrm{x} 6)$ & 0,316047494 \\
\hline $\mathrm{g}(\mathrm{x} 1, \mathrm{x} 4, \mathrm{x} 7)$ & 0,287750417 \\
\hline $\mathrm{g}(\mathrm{x} 1, \mathrm{x} 5, \mathrm{x} 6)$ & 0,298996647 \\
\hline $\mathrm{g}(\mathrm{x} 1, \mathrm{x} 5, \mathrm{x} 7)$ & 0,270397259 \\
\hline $\mathrm{g}(\mathrm{x} 1, \mathrm{x} 6, \mathrm{x} 7)$ & 0,443928846 \\
\hline $\mathrm{g}(\mathrm{x} 2, \mathrm{x} 3, \mathrm{x} 4)$ & 0,469484799 \\
\hline $\mathrm{g}(\mathrm{x} 2, \mathrm{x} 3, \mathrm{x} 5)$ & 0,4540732 \\
\hline $\mathrm{g}(\mathrm{x} 2, \mathrm{x} 3, \mathrm{x} 6)$ & 0,608189196 \\
\hline $\mathrm{g}(\mathrm{x} 2, \mathrm{x} 3, \mathrm{x} 7)$ & 0,585071797 \\
\hline $\mathrm{g}(\mathrm{x} 2, \mathrm{x} 4, \mathrm{x} 5)$ & 0,175842259 \\
\hline $\mathrm{g}(\mathrm{x} 2, \mathrm{x} 4, \mathrm{x} 6)$ & 0,359368847 \\
\hline $\mathrm{g}(\mathrm{x} 2, \mathrm{x} 4, \mathrm{x} 7)$ & 0,331839858 \\
\hline $\mathrm{g}(\mathrm{x} 2, \mathrm{x} 5, \mathrm{x} 6)$ & 0,342780823 \\
\hline $\mathrm{g}(\mathrm{x} 2, \mathrm{x} 5, \mathrm{x} 7)$ & 0,314957729 \\
\hline $\mathrm{g}(\mathrm{x} 2, \mathrm{x} 6, \mathrm{x} 7)$ & 0,483779021 \\
\hline $\mathrm{g}(\mathrm{x} 3, \mathrm{x} 4, \mathrm{x} 5)$ & 0,3889868 \\
\hline $\mathrm{g}(\mathrm{x} 3, \mathrm{x} 4, \mathrm{x} 6)$ & 0,549982799 \\
\hline $\mathrm{g}(\mathrm{x} 3, \mathrm{x} 4, \mathrm{x} 7)$ & 0,525833399 \\
\hline $\mathrm{g}(\mathrm{x} 3, \mathrm{x} 5, \mathrm{x} 6)$ & 0,535431199 \\
\hline $\mathrm{g}(\mathrm{x} 3, \mathrm{x} 5, \mathrm{x} 7)$ & 0,511023799 \\
\hline $\mathrm{g}(\mathrm{x} 3, \mathrm{x} 6, \mathrm{x} 7)$ & 0,659119794 \\
\hline $\mathrm{g}(\mathrm{x} 4, \mathrm{x} 5, \mathrm{x} 6)$ & 0,272726141 \\
\hline $\mathrm{g}(\mathrm{x} 4, \mathrm{x} 5, \mathrm{x} 7)$ & 0,243660976 \\
\hline $\mathrm{g}(\mathrm{x} 4, \mathrm{x} 6, \mathrm{x} 7)$ & 0,42001874 \\
\hline $\mathrm{g}(\mathrm{x} 5, \mathrm{x} 6, \mathrm{x} 7)$ & 0,40407867 \\
\hline
\end{tabular}

\begin{tabular}{|l|r|}
\hline$g(x 1, x 2, x 3)$ & 0,492602199 \\
\hline$g(x 1, x 2, x 4)$ & 0,221723906 \\
\hline$g(x 1, x 2, x 5)$ & 0,203665353 \\
\hline$g(x 1, x 2, x 6)$ & 0,384250882 \\
\hline$g(x 1, x 2, x 7)$ & 0,357163052 \\
\hline$g(x 1, x 3, x 4)$ & 0,4292358 \\
\hline$g(x 1, x 3, x 5)$ & 0,4133942 \\
\hline$g(x 1, x 3, x 6)$ & 0,571810198 \\
\hline$g(x 1, x 3, x 7)$ & 0,548047798 \\
\hline$g(x 1, x 4, x 5)$ & 0,127400318 \\
\hline$g(x 1, x 4, x 6)$ & 0,316047494 \\
\hline$g(x 1, x 4, x 7)$ & 0,287750417 \\
\hline$g(x 1, x 5, x 6)$ & 0,298996647 \\
\hline$g(x 1, x 5, x 7)$ & 0,270397259 \\
\hline$g(x 1, x 6, x 7)$ & 0,443928846 \\
\hline$g(x 2, x 3, x 4)$ & 0,469484799 \\
\hline$g(x 2, x 3, x 5)$ & 0,4540732 \\
\hline$g(x 2, x 3, x 6)$ & 0,608189196 \\
\hline$g(x 2, x 3, x 7)$ & 0,585071797 \\
\hline$g(x 2, x 4, x 5)$ & 0,175842259 \\
\hline$g(x 2, x 4, x 6)$ & 0,359368847 \\
\hline$g(x 2, x 4, x 7)$ & 0,331839858 \\
\hline$g(x 2, x 5, x 6)$ & 0,342780823 \\
\hline$g(x 2, x 5, x 7)$ & 0,314957729 \\
\hline$g(x 2, x 6, x 7)$ & 0,483779021 \\
\hline$g(x 3, x 4, x 5)$ & 0,3889868 \\
\hline$g(x 3, x 4, x 6)$ & 0,549982799 \\
\hline$g(x 3, x 4, x 7)$ & 0,525833399 \\
\hline$g(x 3, x 5, x 6)$ & 0,535431199 \\
\hline$g(x 3, x 5, x 7)$ & 0,511023799 \\
\hline$g(x 3, x 6, x 7)$ & 0,659119794 \\
\hline$g(x 4, x 5, x 6)$ & 0,272726141 \\
\hline$g(x 4, x 5, x 7)$ & 0,243660976 \\
\hline$g(x 4, x 6, x 7)$ & 0,42001874 \\
\hline$g(x 5, x 6, x 7)$ & 0,40407867 \\
\hline
\end{tabular}




\begin{tabular}{|l|r|}
\hline$g(x 1, x 2, x 3, x 4)$ & 0,522296961 \\
\hline$g(x 1, x 2, x 3, x 5)$ & 0,50744958 \\
\hline$g(x 1, x 2, x 3, x 6)$ & 0,65592339 \\
\hline$g(x 1, x 2, x 3, x 7)$ & 0,633652318 \\
\hline$g(x 1, x 2, x 4, x 5)$ & 0,239404674 \\
\hline$g(x 1, x 2, x 4, x 6)$ & 0,416212353 \\
\hline$g(x 1, x 2, x 4, x 7)$ & 0,389691201 \\
\hline$g(x 1, x 2, x 5, x 6)$ & 0,400231617 \\
\hline$g(x 1, x 2, x 5, x 7)$ & 0,373427127 \\
\hline$g(x 1, x 2, x 6, x 7)$ & 0,536067871 \\
\hline$g(x 1, x 3, x 4, x 5)$ & 0,444745993 \\
\hline$g(x 1, x 3, x 4, x 6)$ & 0,599847929 \\
\hline$g(x 1, x 3, x 4, x 7)$ & 0,576582638 \\
\hline$g(x 1, x 3, x 5, x 6)$ & 0,585829063 \\
\hline$g(x 1, x 3, x 5, x 7)$ & 0,562315218 \\
\hline$g(x 1, x 3, x 6, x 7)$ & 0,704989418 \\
\hline$g(x 1, x 4, x 5, x 6)$ & 0,332741637 \\
\hline$g(x 1, x 4, x 5, x 7)$ & 0,304740548 \\
\hline$g(x 1, x 4, x 6, x 7)$ & 0,474641854 \\
\hline$g(x 2, x 3, x 4, x 5)$ & 0,484573988 \\
\hline$g(x 2, x 3, x 4, x 6)$ & 0,635465878 \\
\hline$g(x 2, x 3, x 4, x 7)$ & 0,612832095 \\
\hline$g(x 2, x 3, x 5, x 6)$ & 0,621827537 \\
\hline$g(x 2, x 3, x 5, x 7)$ & 0,598951946 \\
\hline$g(x 2, x 3, x 6, x 7)$ & 0,737753436 \\
\hline$g(x 3, x 4, x 5, x 6)$ & 0,564229979 \\
\hline$g(x 3, x 4, x 5, x 7)$ & 0,540333182 \\
\hline$g(x 3, x 4, x 6, x 7)$ & 0,685331008 \\
\hline$g(x 4, x 5, x 6, x 7)$ & 0,435625344 \\
\hline
\end{tabular}

\begin{tabular}{|l|l|l|l|}
\hline$g(x 1, x 2, x 3, x 4, x 5)$ & 0,536833735 \\
\hline$g(x 1, x 2, x 3, x 4, x 6)$ & 0,682201473 \\
\hline$g(x 1, x 2, x 3, x 4, x 7)$ & 0,660396312 \\
\hline$g(x 1, x 2, x 3, x 5, x 6)$ & 0,669062431 \\
\hline$g(x 1, x 2, x 3, x 5, x 7)$ & 0,647024315 \\
\hline$g(x 1, x 2, x 3, x 6, x 7)$ & 0,780744283 \\
\hline$g(x 1, x 2, x 33, x 4, x 5, x 7)$ & 0,673488566 \\
\hline$g(x 1, x 2, x 4, x 5, x 6)$ & 0,431858772 \\
\hline$g$
\end{tabular}$\quad$\begin{tabular}{|l|l|}
\hline$g(x 1, x 2, x 2, x 3, x 4, x 4, x 6, x 7)$ & 0,792577697 \\
\hline$g(x 2, x 3, x 4, x 5, x 6, x 7)$ & 0,774345771 \\
\hline
\end{tabular}

$\mathrm{g}(\mathrm{x} 1, \mathrm{x} 2, \mathrm{x} 3, \mathrm{x} 4, \mathrm{x} 5, \mathrm{x} 6, \mathrm{x} 7)$

\begin{tabular}{ll}
$\mathrm{g}(\mathrm{x} 1, \mathrm{x} 2, \mathrm{x} 4, \mathrm{x} 5, \mathrm{x} 7)$ & 0,405615031 \\
\hline
\end{tabular}

$\begin{array}{ll}\mathrm{g}(\mathrm{x} 1, \mathrm{x} 2, \mathrm{x} 4, \mathrm{x} 6, \mathrm{x} 7) & 0,564853332\end{array}$

\begin{tabular}{l|l}
$\mathrm{g}(\mathrm{x} 1, \mathrm{x} 2, \mathrm{x} 5, \mathrm{x} 6, \mathrm{x} 7)$ & 0,550460602
\end{tabular}

\begin{tabular}{l|l}
$\mathrm{g}(\mathrm{x} 1, \mathrm{x} 3, \mathrm{x} 4, \mathrm{x} 5, \mathrm{x} 6)$ & 0,613573519
\end{tabular}

\begin{tabular}{l|l}
$\mathrm{g}(\mathrm{x} 1, \mathrm{x} 3, \mathrm{x} 4, \mathrm{x} 5, \mathrm{x} 7)$ & 0,590551584
\end{tabular}

\begin{tabular}{ll}
$\mathrm{g}(\mathrm{x} 1, \mathrm{x} 3, \mathrm{x} 4, \mathrm{x} 6, \mathrm{x} 7)$ & 0,73024104 \\
\hline
\end{tabular}

\begin{tabular}{l|l}
$\mathrm{g}(\mathrm{x} 1, \mathrm{x} 3, \mathrm{x} 5, \mathrm{x} 6, \mathrm{x} 7)$ & 0,717615229
\end{tabular}

$\begin{array}{ll}\mathrm{g}(\mathrm{x} 1, \mathrm{x} 4, \mathrm{x} 5, \mathrm{x} 6, \mathrm{x} 7) & 0,489677101\end{array}$

$\mathrm{g}(\mathrm{x} 2, \mathrm{x} 3, \mathrm{x} 4, \mathrm{x} 5, \mathrm{x} 6) \quad 0,648818905$

$\mathrm{g}(\mathrm{x} 2, \mathrm{x} 3, \mathrm{x} 4, \mathrm{x} 5, \mathrm{x} 7) \quad 0,626421871$

\begin{tabular}{l|l}
$\mathrm{g}(\mathrm{x} 2, \mathrm{x} 3, \mathrm{x} 4, \mathrm{x} 6, \mathrm{x} 7)$ & 0,762319634 \\
\hline
\end{tabular}

\begin{tabular}{ll}
$\mathrm{g}(\mathrm{x} 3, \mathrm{x} 4, \mathrm{x} 5, \mathrm{x} 6, \mathrm{x} 7)$ & 0,698162446 \\
\hline
\end{tabular}

\section{Results}

The construction of Sugeno integral in the strategies order follows equation (6):

$$
\int f(x) d g_{\lambda}=M_{i=1}^{n} a x\left\{\operatorname{Min}\left[f\left(x_{(i)}, g\left(A_{(i)}\right)\right]\right\}\right.
$$

Where $f\left(x_{(1)}\right) \leq f\left(x_{(2)}\right) \leq \ldots \leq f\left(x_{(n)}\right)$.

- $\quad$ For $\mathrm{S}^{\mathrm{QS}}$, we have:

$\mathrm{f}\left(\mathrm{x}_{4}\right)=\mathrm{g}_{14}=0.2 ; \mathrm{f}\left(\mathrm{x}_{7}\right)=\mathrm{g}_{17}=0.5 ; \mathrm{f}\left(\mathrm{x}_{3}\right)=\mathrm{g}_{13}=0.5 ; \quad \mathrm{f}\left(\mathrm{x}_{6}\right)=\mathrm{g}_{16}=0.7 ; \quad \mathrm{f}\left(\mathrm{x}_{5}\right)=\mathrm{g}_{15}=0.8 ; \mathrm{f}\left(\mathrm{x}_{2}\right)=\mathrm{g}_{12}=0.9 ; \quad \mathrm{f}\left(\mathrm{x}_{1}\right)=\mathrm{g}_{11}=1$.

So, $f\left(x_{(4)}\right) \leq f\left(x_{(7)}\right)=f\left(x_{(3)}\right) \leq f\left(x_{(6)}\right) \leq f\left(x_{(5)}\right) \leq f\left(x_{(2)}\right) \leq f\left(x_{(1)}\right)$

$\mathrm{S}^{\mathrm{QS}}=\int f d g_{\lambda}=\max \left(\min \left(\mathrm{f}\left(\mathrm{x}_{4}\right), \mathrm{g}_{\lambda}\left(\mathrm{x}_{1}, \mathrm{x}_{2}, \mathrm{x}_{3}, \mathrm{x}_{4}, \mathrm{x}_{5}, \mathrm{x}_{6}, \mathrm{x}_{7}\right)\right) ; \min \left(\mathrm{f}\left(\mathrm{x}_{7}\right), \mathrm{g}_{\lambda}\left(\mathrm{x}_{1}, \mathrm{x}_{2}, \mathrm{x}_{3}, \mathrm{x}_{5}, \mathrm{x}_{6}, \mathrm{x}_{7}\right)\right) ;\right.$

$\min \left(\mathrm{f}\left(\mathrm{x}_{3}\right), \mathrm{g}_{\lambda}\left(\mathrm{x}_{1}, \mathrm{x}_{2}, \mathrm{x}_{3}, \mathrm{x}_{5}, \mathrm{x}_{6}\right)\right) ; \min \left(\mathrm{f}\left(\mathrm{x}_{6}\right), \mathrm{g}_{\lambda}\left(\mathrm{x}_{1}, \mathrm{x}_{2}, \mathrm{x}_{5}, \mathrm{x}_{6}\right)\right) ; \min \left(\mathrm{f}\left(\mathrm{x}_{5}\right), \mathrm{g}_{\lambda}\left(\mathrm{x}_{1}, \mathrm{x}_{2}, \mathrm{x}_{5}\right)\right) ; \min \left(\mathrm{f}\left(\mathrm{x}_{2}\right), \mathrm{g}_{\lambda}\left(\mathrm{x}_{1}, \mathrm{x}_{2}\right)\right) ; \min \left(\mathrm{f}\left(\mathrm{x}_{1}\right)\right.$, $\left.\mathrm{g}_{\lambda}\left(\mathrm{x}_{1}\right)\right)$

$\mathrm{S}^{\mathrm{QS}}=\int f d g_{\lambda}=\max (\min (0.2 ; 1) ; \min (0.5 ; 0.792577697) ; \min (0.5 ; 0.669062431) ; \min (0.7 ; 0.400231617) ; \min (0.8 ;$ $0.203665353) ; \min (0.9 ; 0,1856068) ; \min (1 ; 0.07))$

$$
\mathrm{S}^{\mathrm{QS}}=\max (0.2 ; 0.5 ; 0.5 ; 0.4 ; 0.203 ; 0.18 ; 0.07)
$$

$$
\mathrm{S}^{\mathrm{QS}}=0.5
$$


- $\quad$ For $\mathrm{S}^{\mathrm{HR}}$, we have:

$$
\begin{gathered}
\mathrm{f}\left(\mathrm{x}_{5}\right)=\mathrm{g}_{25}=0.5 ; \mathrm{f}\left(\mathrm{x}_{7}\right)=\mathrm{g}_{27}=0.7 ; \mathrm{f}\left(\mathrm{x}_{3}\right)=\mathrm{g}_{23}=0.7 ; \mathrm{f}\left(\mathrm{x}_{1}\right)=\mathrm{g}_{21}=0.8 ; \mathrm{f}\left(\mathrm{x}_{2}\right)=\mathrm{g}_{22}=0.8 ; \mathrm{f}\left(\mathrm{x}_{4}\right)=\mathrm{g}_{24}=0.8 ; \mathrm{f}\left(\mathrm{x}_{6}\right)=\mathrm{g}_{26}=1 \\
\text { So, } f\left(x_{(5)}\right) \leq f\left(x_{(7)}\right)=f\left(x_{(3)}\right) \leq f\left(x_{(1)}\right)=f\left(x_{(2)}\right)=f\left(x_{(4)}\right) \leq f\left(x_{(6)}\right) \\
\mathrm{S}^{\mathrm{HR}}=\int f d g_{\lambda}=\max \left(\min \left(\mathrm{f}\left(\mathrm{x}_{5}\right), \mathrm{g}_{\lambda}\left(\mathrm{x}_{1}, \mathrm{x}_{2}, \mathrm{x}_{3}, \mathrm{x}_{4}, \mathrm{x}_{5}, \mathrm{x}_{6}, \mathrm{x}_{7}\right)\right) ; \min \left(\mathrm{f}\left(\mathrm{x}_{7}\right), \mathrm{g}_{\lambda}\left(\mathrm{x}_{1}, \mathrm{x}_{2}, \mathrm{x}_{3}, \mathrm{x}_{4}, \mathrm{x}_{6}, \mathrm{x}_{7}\right)\right) ;\right.
\end{gathered}
$$

$\min \left(\mathrm{f}\left(\mathrm{x}_{3}\right), \mathrm{g}_{\lambda}\left(\mathrm{x}_{1}, \mathrm{x}_{2}, \mathrm{x}_{3}, \mathrm{x}_{4}, \mathrm{x}_{6}\right)\right) ; \min \left(\mathrm{f}\left(\mathrm{x}_{1}\right), \mathrm{g}_{\lambda}\left(\mathrm{x}_{1}, \mathrm{x}_{2}, \mathrm{x}_{4}, \mathrm{x}_{6}\right)\right) ; \min \left(\mathrm{f}\left(\mathrm{x}_{2}\right), \mathrm{g}_{\lambda}\left(\mathrm{x}_{2}, \mathrm{x}_{4}, \mathrm{x}_{6}\right)\right) ; \min \left(\mathrm{f}\left(\mathrm{x}_{4}\right), \mathrm{g}_{\lambda}\left(\mathrm{x}_{4}, \mathrm{x}_{6}\right)\right) ; \min \left(\mathrm{f}\left(\mathrm{x}_{6}\right), \mathrm{g}_{\lambda}\right.$

$$
\begin{aligned}
& \mathrm{S}^{\mathrm{HR}}=\int f d g_{\lambda}=\max (\min (0.5 ; 1) ; \min (0.7 ; 0.8) ; \min (0.7 ; 0.68) ; \min (0.8 ; 0.42) ; \min (0.8 ; 0.36) ; \\
& \min (0.8 ; 0.25) ; \min (1 ; 0.22)) \\
& \mathrm{S}^{\mathrm{HR}}=\max (0.5 ; 0.7 ; 0.68 ; 0.42 ; 0.36 ; 0.25 ; 0.22) \\
& \mathrm{S}^{\mathrm{HR}}=0.7
\end{aligned}
$$

- $\quad$ For $\mathrm{S}^{\mathrm{MM}}$, we have:

$$
\begin{gathered}
\mathrm{f}\left(\mathrm{x}_{4}\right)=\mathrm{g}_{34}=0.1 ; \mathrm{f}\left(\mathrm{x}_{5}\right)=\mathrm{g}_{35}=0.5 ; \mathrm{f}\left(\mathrm{x}_{6}\right)=\mathrm{g}_{36}=0.7 ; \mathrm{f}\left(\mathrm{x}_{1}\right)=\mathrm{g}_{21}=0.8 ; \mathrm{f}\left(\mathrm{x}_{2}\right)=\mathrm{g}_{32}=0.9 ; \mathrm{f}\left(\mathrm{x}_{7}\right)=\mathrm{g}_{37}=0,9 ; \mathrm{f}\left(\mathrm{x}_{3}\right)=\mathrm{g}_{33}=1 \\
\text { So, } f\left(x_{(4)}\right) \leq f\left(x_{(5)}\right) \leq f\left(x_{(6)}\right) \leq f\left(x_{(1)}\right) \leq f\left(x_{(2)}\right)=f\left(x_{(7)}\right) \leq f\left(x_{(3)}\right) \\
\mathrm{S}^{\mathrm{MM}}=\int f d g_{\lambda}=\max \left(\min \left(\mathrm{f}\left(\mathrm{x}_{4}\right), \mathrm{g}_{\lambda}\left(\mathrm{x}_{1}, \mathrm{x}_{2}, \mathrm{x}_{3}, \mathrm{x}_{4}, \mathrm{x}_{5}, \mathrm{x}_{6}, \mathrm{x}_{7}\right)\right) ; \min \left(\mathrm{f}\left(\mathrm{x}_{5}\right), \mathrm{g}_{\lambda}\left(\mathrm{x}_{1}, \mathrm{x}_{2}, \mathrm{x}_{3}, \mathrm{x}_{5}, \mathrm{x}_{6}, \mathrm{x}_{7}\right)\right) ;\right.
\end{gathered}
$$

$\min \left(f\left(x_{6}\right), g_{\lambda}\left(x_{1}, x_{2}, x_{3}, x_{6}, x_{7}\right)\right) ; \min \left(f\left(x_{1}\right), g_{\lambda}\left(x_{1}, x_{2}, x_{3}, x_{7}\right)\right) ; \min \left(f\left(x_{2}\right), g_{\lambda}\left(x_{2}, x_{3}, x_{7}\right)\right) ; \min \left(f\left(x_{7}\right), g_{\lambda}\left(x_{3}, x_{7}\right)\right) ; \min \left(f\left(x_{3}\right), g_{\lambda}\right.$

$\left.\left(\mathrm{x}_{3}\right)\right)$

$$
\begin{aligned}
& \mathrm{S}^{\mathrm{MM}}=\int f d g_{\lambda}=\max (\min (0.1 ; 1) ; \min (0.5 ; 0,79) ; \min (0.7 ; 0.78) ; \min (0.8 ; 0.63) ; \min (0.9 ; 0.58) ; \\
& \min (0.9 ; 0.49) ; \min (1 ; 0.34)) \\
& \mathrm{S}^{\mathrm{MM}}=\max (0.1 ; 0.5 ; 0.7 ; 0.63 ; 0.58 ; 0.49 ; 0.34) \\
& \mathrm{S}^{\mathrm{MM}}=0.7
\end{aligned}
$$

The interpretation of Sugeno integral in the strategy ranking gives $S^{\mathrm{HR}}=\mathrm{S}^{\mathrm{MM}} \geq \mathrm{S}^{\mathrm{QS}}$

In the linear model, we found in the first rank "Machine Management" strategy with the overall performance equal to 0.831 , then the "Human resource" strategy with 0.789 , followed by the "Quality security" strategy with 0.6535 .

The ranking of "Human resource" strategy was improved, occupying the first place tied with "Machine Management" strategy with the score of 0.7 . In this case, the priority of action would be first to implement "Human resource" strategy or "Machine Management" strategy, and second "Quality security" strategy.

That adjustment can substitute for other expensive strategies such whom concerning

\section{Discussion}

A technique for measuring the causal interactions between the different factors affecting the global performance has been designed and applied. For the top management the foremost profit is the performance formulation of various measures into a dimensionless item at all the corporation stages.

The second benefit is associated with the decision making help for adopting the suitable strategy. Administrators frequently vacillate between different strategies permit them to confirm their perception.

Our model has several suppleness for dealing with in the intrinsic and extrinsic environment changes, but only below the suppositions of small differences of the objective standards and of the weight and the relations of the performance factors.

At last, the proposed method is not exclusive to our case study. It can duplicate across different manufacturers where enough expertise regarding particular circumstances is indispensable to describe the weight and the relations of criterion.

\section{Conclusion}

The Sugeno integral as an operator of aggregation is well fitted to deal with the interactions between the performance factors. An industrial application has permitted us to show the pertinence of such method. The algorithm studied can be used to determine the best distribution of resources on performance criteria.

This method has proven its efficiency by structuring assessment of human subjective decision making by using $\lambda$-fuzzy measures and sugeno integrals.

Certainly, this approach requires a great manager proficiency of the method: to make the structure of the global 
performance to compare a number of performance situations in order to identify the Sugeno parameters through an AHP exercise.

Perspectives for future research will concern the integration of cost parameters in order to obtain the best action plan to obtain a fixed performance improvement at the lowest cost to reach a better overall performance.

\section{Acknowledgments}

We thank Mr. Abdelhak MOUNIR, leader of the Moroccan Association of Automotive Industry, Chairman of the Moroccan Institute for Training in Automotive Industry (IFMIAC) for his assistance in the preparation of this manuscript.

\section{References}

AMICA. (2012). Moroccan automotive sector. Moroccan Association of Automotive Industry, Casablanca, Morocco. Retrieved from http://www.unido.or.jp/download/AMICA-PRESENTATION_Japon.pdf

Berrah, L. (2013). Quantifying performance in manufacturing firms: The statement of the objectives to the definition of indicator systems. Thesis Habilitation research, Savoie University, Annecy, France. Retrieved from http://www.polytech.univ-savoie.fr/fileadmin/polytech_autres_sites/sites/listic/Theses/ManuscritHDR_Lam iaBerrah.pdf

Berrah, L., \& Clivelle, V. (2007). Towards an aggregation performance measurement system model in a supply chain context. Computers in Industry, 58, 709-719. http://dx.doi.org/10.1016/j.compind.2007.05.012

Berrah, L., Mauris, G., \& Montmain, J. (2008). Monitoring the Improvement of an overall industrial performance based on a Choquet integral aggregation. Omega, 36, 340-351. http://dx.doi.org/10.1016/j.omega.2006.02.009

Berrah, L., Mauris, G., \& Vernadat, F. (2004). Information aggregation in industrial performance measurement: rationales, issues and definitions. International Journal of Production Research, 42(20), 4271-4293. http://dx.doi.org/10.1080/00207540410001716534

Berrah, L., Mauris, G., Haurat, A., \& Foulloy, L. (2000). Global vision and performance indicators for an industrial improvement approach. Computers in Industry, 43(3), 211-225. http://dx.doi.org/10.1016/S0166-3615(00)00070-1

Bititci, U. S., Suwignjo, P., \& Carrie, A. S. (2001). Strategy management through quantitative modeling of performance measurement system. International Journal of Production Economics, 69, 15-22. http://dx.doi.org/10.1016/S0925-5273(99)00113-9

Chahid, M. T., Alami, J. E., Soulhi, A., \& Alami, N. E. (2014). Performance Measurement Model for Moroccan Automotive Suppliers Using PMQ and AHP. Modern Applied Science, 8(6). http://dx.doi.org/:10.5539/mas.v8n6p13

Chen, C. C. (2008). An objective-oriented and product-line based manufacturing performance measurement. $\begin{array}{lllll}\text { International Journal of Production } & \text { Economics, } & 112, & 380-390 .\end{array}$ http://dx.http://dx.doi.org/.org/10.1016/j.ijpe.2007.03.016

Clivelle, V. (2004). Systemic approach and multicriteria method for the definition of performance indicators system. Thesis for the degree of Doctor of Philosophy. Savoie University, Annecy, France. Retrieved from www.polytech.univ-savoie.fr/fileadmin/polytech_autres_sites/sites/listic/Theses/thesecliville.pdf

Clivelle, V., Berrah, L., \& Mauris, G. (2006). Quantitative expression and aggregation of performance measurements based on the MACBETH multi-criteria method. International Journal of Production Economics, 105, 171-189. http://dx.doi.org/10.1016/j.ijpe.2006.03.002

Ducq, Y., Vallespir, B., \& Doumeingts, G. (2001). Coherence analysis methods for production systems by performance aggregation. International Journal of Production Economics, 7, 23-37. http://dx.doi.org/ 10.1016/S0925-5273(00)00054-2

Azzone, G., Masella, C., \& Bertele, U. (1991). Design of performance measures for time based companies. International Journal of Operations \& Production Management, 11(3), 77-85. http://dx.doi.org/10.1108/01443579110143412

Buyukozkan, G., \& Ruan, D. (2010). Choquet integral based aggregation approach to software development risk assessment. Information Sciences, 180, 441-451. http://dx.doi.org/10.1016/j.ins.2009.09.009 
Grabisch, M. (1995). Fuzzy integral in multicriteria decision making. Fuzzy Sets and Systems, 69(3), 279-298. http://dx.doi.org/ 10.1016/0165-0114(94)00174-6

Hernandez-Matias, J. C., Vizan, A., Perez-Garcia, J., \& Rios, J. (2008). An integrated modelling framework to support manufacturing system diagnosis for continuous improvement. Robotic and Computer integrated Manufacturing, 24, 187-199. http://dx.doi.org/10.1016/j.rcim.2006.10.003

Jeng, D. J. (2011). Selection of an Improvement Strategy in Internal Service Operations: The MCDM Approach with Fuzzy AHP and Nonadditive Fuzzy Integral. International Journal of Innovative Computing, Information and Control, 8(8), 5917-5933.

Kueng, P., \& Krahn, A. J. (1999). Building a process performance measurement system: some early experiences. Journal of Scientific, and Industrial Research, 58, 149-159.

Melnyk, S. A., Bititci, U. S., Platts, K., Tobias, J., \& Anderson, B. (2014). Is performance measurement and management fit for the future? Management Accounting Research, 25(2), 173-186. http://dx.doi.org/10.1016/j.mar.2013.07.007

Michalska, J. (2005). The usage of the balanced scorecard for the estimation of the enterprise's effectiveness. $\begin{array}{lllll}\text { Journal of Materials Processing Technology, } & \text { 162-163, }\end{array}$ http://dx.doi.org/10.1016/j.jmatprotec.2005.02.227

Neely, A. (1999). The performance measurement revolution: why now and what next? International Journal of $\begin{array}{llll}\text { Operations \& Production } \quad \text { Management, } & \text { 19(2), }\end{array}$ http://dx.http://dx.doi.org/.org/10.1108/01443579910247437

Popova, V., \& Sharpanskykh, A. (2010). Modeling organizational performance indicators. Information Systems, 35, 505-527. http://dx.doi.org/ 10.1016/j.is.2009.12.001

Reznik, L., \& Dabke, K. P. (2004). Measurement models: application of intelligent methods. Measurement, 35, 47-58. http://dx.doi.org/ 10.1016/j.measurement.2003.08.020

Subramanian, N., \& Ramanathan, R. (2012). A review of applications of Analytic Hierarchy Process in operations management. International Journal of Production Economics, 138, 215-241. http://dx.doi.org/10.1016/j.ijpe.2012.03.036.

Sugeno, M., \& Takahiro, Y. (1993). “A fuzzy-Logic-Based Approach to Qualitative Modeling”, IEEE Transactions on Fuzzy Systems, 1(1), 7-31. http://dx.doi.org/10.1109/TFUZZ.1993.390281

Suwingjo, P., Bititci, U. S., \& Carrie, A. S. (2000). Quantitative models for performance measurement system", International Journal of Production Economics, 64, 231-241. http://dx.doi.org/10.1016/S0925-5273(99)00061-4

Takagi, T., \& Sugeno, M. (1985). Fuzzy Identification of Systems and Its Applications to Modeling and Control. IEEE Transactions on Systems, Man, and Cybernetics, smc-15(1), 116-132. http://dx.doi.org/ 10.1109/TSMC.1985.6313399.

Vaidya, O. S., \& Kumar, S. (2006). Analytic hierarchy process: an overview of applications. European Journal of Operational Research, 169, 1-29. http://dx.doi.org/10.1016/j.ejor.2007.01.004

Wang, Y., \& Chen, Y. (2014). A Comparison of Mamdani and Sugeno Fuzzy Inference Systems for Traffic Flow Prediction. Journal of Computers, 9(1), 12-21. http://dx.doi.org/ 10.4304/jcp.9.1.12-21

\section{Copyrights}

Copyright for this article is retained by the author(s), with first publication rights granted to the journal.

This is an open-access article distributed under the terms and conditions of the Creative Commons Attribution license (http://creativecommons.org/licenses/by/3.0/). 